ISSN: 0514-7336

DOI: http://dx.doi.org/10.14201/zephyrus201372183193

\title{
UN EJEMPLAR DE CYPRAEA PANTHERINA EN UNA TUMBA ALTOIMPERIAL DE AUGUSTA EMERITA
}

\section{A specimen of Cypraea pantherina in a grave of Augusta Emerita during High Roman Empire}

\author{
Antonio Rodríguez-Hidalgo*, Víctor Gibello Bravo**, Andrea Menéndez Menéndez**, Diego \\ SANABRIA Murillo** y Fernando SÁnCHEZ Hidalgo** \\ * Institut Catalá de Paleoecologia Humana i Evolució Social. Univ. Rovira i Virgili. C/ Marcel.li Domingo, s/n. \\ 43007 Tarragona. Correo-e: arodriguez@iphes.cat \\ ** Arqveocheck S.L.U. C/ Cervantes, 14, bloque 2, locales 2-3.06800 Mérida.Correo-e: victor.gibello@arqveo- \\ check.com; andreamdz@gmail.com; disanabria@yahoo.esy fernando.sanchez@arqveocheck.com
}

Recepción: 30/08/2012; Revisión: 12/04/2013; Aceptación: 31/05/2013

BIBLID [0514-7336 (2013) LXXII, julio-diciembre; 183-193]

RESUMEN: En este trabajo se presenta un ejemplar de concha de molusco marino recuperado como parte de un depósito funerario de época altoimperial. El elemento procede de una tumba excavada en la ciudad de Mérida (España). El análisis taxonómico indica su pertenencia a la especie Cypraea pantherina. Se trata de un elemento exótico de procedencia indopacífica incluido muy ocasionalmente en depósitos funerarios en el mundo romano desde el s. I a. C. La especie suele aparecer asociada a tumbas femeninas por sus connotaciones relativas a la fertilidad, la procreación y el buen parto. El caso emeritense es el único del que se tiene noticia hasta el momento en la Península Ibérica, permitiendo así ampliar nuestro conocimiento sobre la distribución de especies exóticas procedentes de mares lejanos mediante la actividad humana.

Palabras clave: Arqueomalacología. Concha marina. Cauris. Depósito funerario. Ritos de fertilidad. Siglo I d. C.

ABSTRACT: In this brief report, we present a specimen of the marine mollusk shell recovered as part of a Roman burial deposit of High-imperial period. The element comes from a tomb excavated in the city of Merida (Spain). The taxonomic analysis indicates it concerned to the species Cypraea pantherina. It is an exotic element of Indo-Pacific origin, including occasionally as funeral offerings in the Roman world from the first century BC. This species, in particular, is associated with female graves. The shell associates connotations of fertility, good childbirth and procreation. The case of Mérida (Augusta Emerita) is the only one that has been reported in the Iberian Peninsula. This allows to extend this way our knowledge on the distribution of exotic species proceeding from distant seas by means of the human activity.

Key words: Archaeo-Malacology. Seashell. Cowries. Burial deposit. Rites of fertility. First century AD. 


\section{Introducción y contexto arqueológico ${ }^{1}$}

Durante el año 2009 tuvo lugar la excavación del solar de los Antiguos Cuarteles de Hernán Cortés en su denominada "Fase Terciaria", en el centro de la ciudad de Mérida, Badajoz (Fig. 1). Se trata de un recinto de más de $40000 \mathrm{~m}^{2}$, en el que se intervino una cuarta parte durante la citada fase. Los restos allí documentados indican una dilatada ocupación del espacio desde época altoimperial hasta la actualidad. Destacable es la presencia de un conjunto termal, dos calzadas, seis recintos funerarios romanos de grandes dimensiones y un área de uso cementerial de época islámica ${ }^{2}$. Entre los numerosos objetos recuperados durante la excavación llamó nuestra atención, por su interés arqueomalacológico, una concha de molusco de grandes dimensiones. La concha se encontraba integrada entre los diversos elementos del depósito funerario de una sepultura en caja de ladrillo. En la misma -tumba A39- se hallaron también diversos objetos de vidrio, hueso y bronce.

La presencia de materiales exóticos en depósitos funerarios es una constante desde el surgimiento del comportamiento humano moderno. Entre estos materiales las conchas de moluscos y bivalvos completas, perforadas o formando parte de elementos más complejos aparecen frecuentemente asociadas a enterramientos. En ocasiones las especies fueron elegidas para formar parte de los ajuares y depósitos por sus características estéticas y su abundancia o escasez en el entorno. En otros casos el carácter simbólico de determinadas especies pudo ser el elemento definitorio para que fuesen elegidas como parte de ajuares y depósitos funerarios (Vanhaeren y d'Errico, 2006).

${ }^{1}$ Queremos expresar nuestro agradecimiento a los miembros del equipo de excavación y al personal de Arqveocheck, a J. Márquez y M. Alba, del Consorcio de la Ciudad Histórico Artística y Arqueológica de Mérida, por sus aportaciones y por las imágenes de la Fig. 5. Gracias a J. Martinell, del área de Paleontología de la Univ. de Barcelona, y A. García Barbo, del IPHES, por su ayuda con la identificación taxonómica. ARH es beneficiario del programa de becas FPI del Ministerio de Economía y Competitividad (CGL2012-38434-C03-03).

2 Sánchez Hidalgo, F.: "Memoria de la excavación arqueológica en el antiguo cuartel de Hernán Cortés, Mérida”, informe inédito realizado en 2010.
En esta breve nota nos centramos en la descripción de la concha recuperada como parte del depósito funerario de la tumba A39. A través de la identificación taxonómica, el análisis de las características del elemento y los paralelos disponibles en la literatura se propone una asignación específica y se discute la relevancia del hallazgo para los estudios arqueomalacológicos en la Península Ibérica. La descripción del depósito funerario al que se asocia y de otros elementos contextuales nos permite determinar la cronología del hallazgo y proponer algunas cuestiones relativas a su carácter simbólico.

\section{Contexto arqueológico de la tumba A39}

La disposición de las diversas estructuras del solar queda supeditada, durante al menos tres siglos, a la presencia de dos vías o calzadas empedradas (Fig. 2); la primera, con orientación N-S, proviene de una de las puertas de la ciudad, en una zona próxima al teatro y anfiteatro. Dicha calzada se encuentra enlosada, no posee cloaca y se fecha en torno a mediados del s. I d. C. Se dirige hacia el $\mathrm{N}$ a conectar con la vía que, prolongándose desde el decumanus maximus a su salida por la Puerta de la Villa, se convertiría en la calzada que se dirige a Metellinum y a Toletum, localizada hacia la actual avenida de Extremadura. Asimismo, nuestra calzada se alinea con la vía excavada en la intervención de la arqueóloga Y. Picado (Reg. 8066), que identifica con el romano Camino Viejo de Mirandilla, bien documentado en los últimos años en diversos tramos al $\mathrm{N}$ de la ciudad de Mérida (Picado, 2006: 93, 105-106).

La segunda vía que atraviesa el solar es un camino empedrado, fechado en el s. II d. C., que se encuentra con la vía enlosada hacia el tercio más occidental del solar, a la altura de los edificios que ocupan el sector SO. Para salvar el desnivel de ambas vías en la zona de su cruce, se crea una repavimentación en un pequeño tramo al $s$ del encuentro de las dos calzadas.

Según su distribución espacial en el solar, se documenta en el sector SO una serie de construcciones superpuestas que se inician con un recinto funerario, situado en la margen o de la calzada enlosada. En un momento posterior, se erige un edificio que conserva en su esquina NO una 


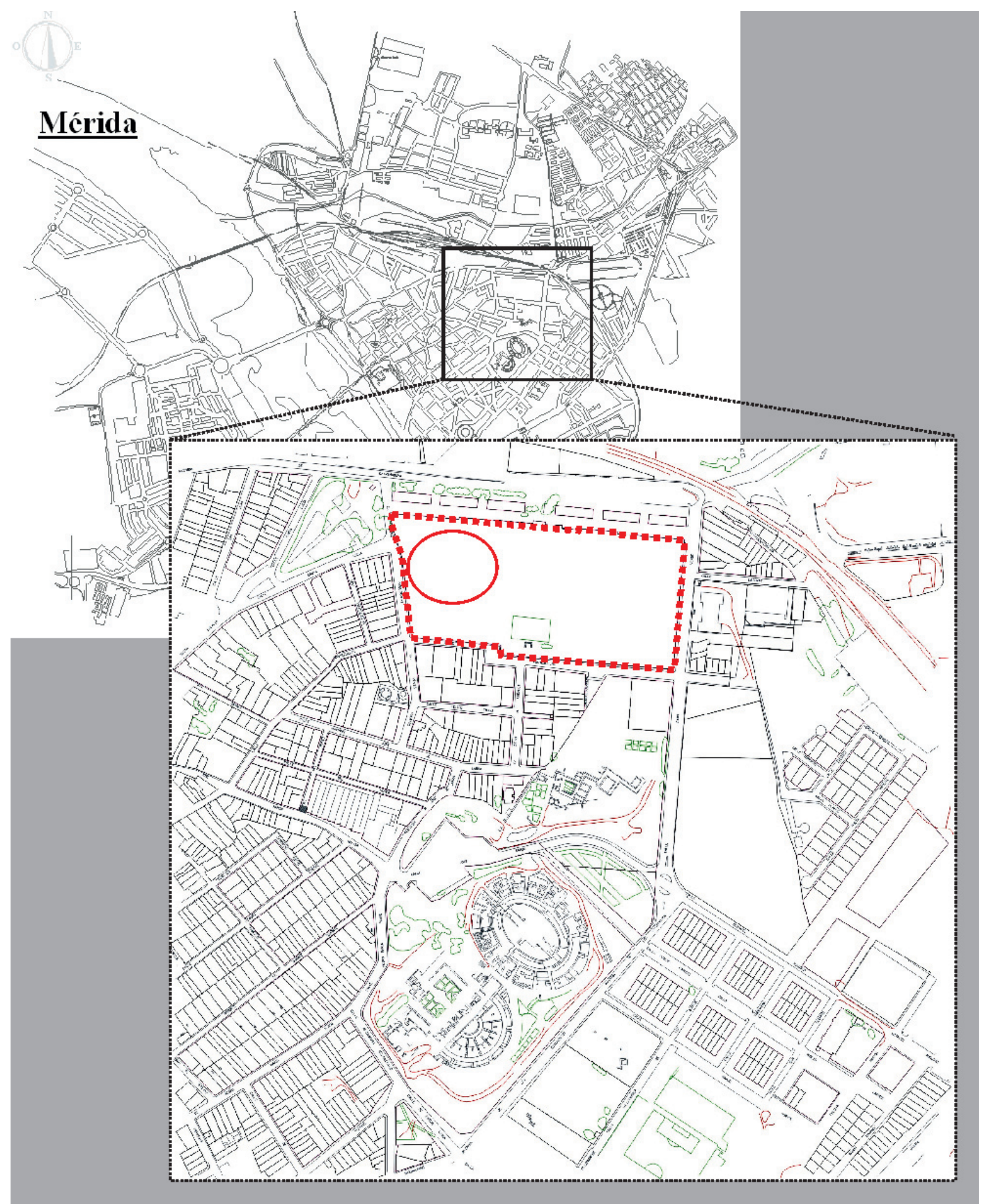

FIG. 1. Plano de situación del solar de los Antiguos Cuarteles de Hernán Cortés sobre el plano catastral de la ciudad de Mérida (Badajoz); se observa su ubicación y detalle de la zona de localización de la tumba A39 (cedido por el Dpto. de Documentación del Consorcio de la Ciudad Histórico-Artistica y Arqueológica de Mérida; E: 1/10.000). 


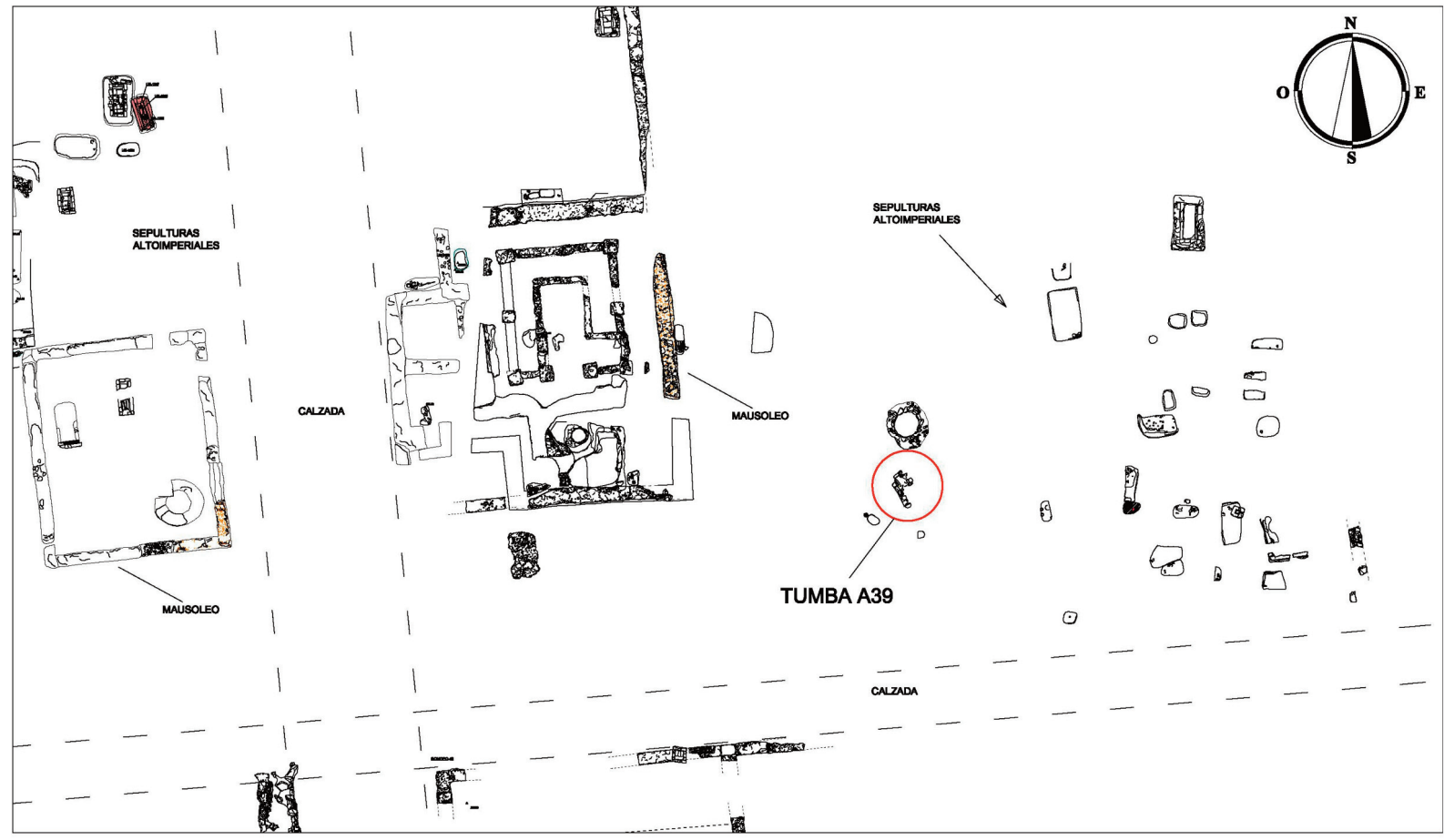

FIG. 2. Sepultura A39 en su contexto (detalle del plano original de D. Sadornil Magdaleno; E: 1/250).

estancia usada como letrina y diversos paramentos y suelos que son amortizados y/o reutilizados por los inmuebles subsiguientes. En otra fase, se implanta una construcción de tipo balnea, una explotación privada para uso público, que ocupa todo el s. III, aunque su creación pudiera remontarse al s. II. La etapa final constructiva queda definida por un edificio residencial, que se levanta a mediados del s. V sobre los inmuebles anteriores, reaprovechando algunos pavimentos de aquellos.

Avanzando por la margen o de la calzada enlosada, al $\mathrm{N}$ de las edificaciones citadas, se documenta otra gran construcción, que es funeraria en origen (ss. II-III) y tiene una segunda fase que amortiza dos enterramientos. En ese momento se procede a la construcción de un pequeño espacio central columnado, seguramente sin techumbre, que tiene un pozo en su interior, cuyo brocal se integra en un suelo de opus signinum. Entre mediados del s. III e inicios del s. IV se entierra allí a un individuo con el rito de inhumación; siendo amortizado el espacio por nuevos recintos con el paso del tiempo. Estos incluyen nuevas compartimentaciones que definen espacios de uso indeterminado, posiblemente agropecuario, fechadas a partir de finales del s. IV y hasta el s. V.

$\mathrm{El}$ sector NO estuvo ocupado entre los ss. I y II por enterramientos individuales de incineración en su mayoría, aunque también se localiza una inhumación. Se documentan también algunas construcciones, como un recinto de planta cuadrangular, con paramentos de opus incertum y refuerzo de sillares en esquina, que conserva un buen alzado, amortizado entre los ss. II y III. Sobre las estructuras anteriores, se reconoce una etapa constructiva con los restos muy deteriorados, a la que sigue otra fase de edificaciones domésticas, que son abandonadas súbitamente a comienzos del s. V.

La parte central del solar, de $\mathrm{S}$ a $\mathrm{N}$, presenta también varios recintos de grandes dimensiones de época altoimperial, entre los que destaca una construcción funeraria de grandes dimensiones $(15 \times 15$ $\mathrm{m})$, diseñada con pozo y triclinio funerario. Hacia el $\mathrm{N}$, se localiza un nuevo recinto monumental mortuorio y numerosos enterramientos individuales de incineración, con alguna inhumación marginal, fechados entre los ss. I y II d. C. 
El tercio oriental del solar muestra en su zona más meridional un extenso nivel de época romana altoimperial, donde se localiza una estructura de opus incertum, con una parte central de signinum que, en su conjunto, se encuentra expoliada. El resto del sector, hacia el $\mathrm{N}$, está ocupado por tres enterramientos de inhumación fechados en el s. III, regidos por la calzada empedrada que se orienta E-O $y$, en su parte más septentrional, tiene tumbas individuales de cremación, de diversas tipologías (mensa, bustum, osario, etc.), entre las que se encuentra la tumba A39, con su particular depósito.

Finalmente, el comienzo de la etapa islámica, se define por la ocupación de un extenso espacio al $s$ del solar como área de enterramientos. Se han localizado cerca de 300 sepulturas que datan de entre los ss. VIII-IX. Los cuerpos se enterraban en fosa simple, orientada habitualmente SO-NE, con el cuerpo recostado sobre su lado derecho.

\section{Tafonomía de la sepultura e interpretación en su área funeraria}

La sepultura A39 es una incineración en caja de ladrillos de planta rectangular, con unas dimensiones conservadas de 1,25 m de longitud x $77 \mathrm{~cm}$ de anchura y $35 \mathrm{~cm}$ de alzado. La tipología de la fábrica es irregular, con los ladrillos dispuestos a soga, con formación en hilera y trabados con barro, que emplea tanto piezas enteras como fragmentarias. Conserva restos de una cubierta, también de ladrillo y toda una esquina de la tumba ha sido seccionada por estructuras contemporáneas (Fig. 1). Su interior se encontraba colmatado por un estrato ceniciento. Este cubría el depósito funerario compuesto principalmente por vidrios, bronces y agujas de hueso además del elemento malacológico objeto del presente estudio. La base de la tumba, de arcilla natural, fue rebajada para darle horizontalidad. Sobre ella se depositaron las cenizas y restos de la cremación, así como parte de su depósito votivo.

La estructura se orienta NO-SE, de igual modo que la mayor parte de los enterramientos de la misma cronología en el sector. En Augusta Emerita, durante época altoimperial se utiliza mayoritariamente esta orientación aunque, si las necesidades del espacio funerario lo requerían, se utilizaba también la SO-NE u otras variantes.

\subsection{El depósito funerario de la tumba A39}

En el interior de la tumba, la UE 2043 o depósito funerario contiene diversos objetos de vidrio, entre los que se incluyen cinco ungüentarios, una botella y una jarrita, además de dos cuencos, incluyendo uno "de costillas" con un grado de conservación excepcional (Fig. 3).
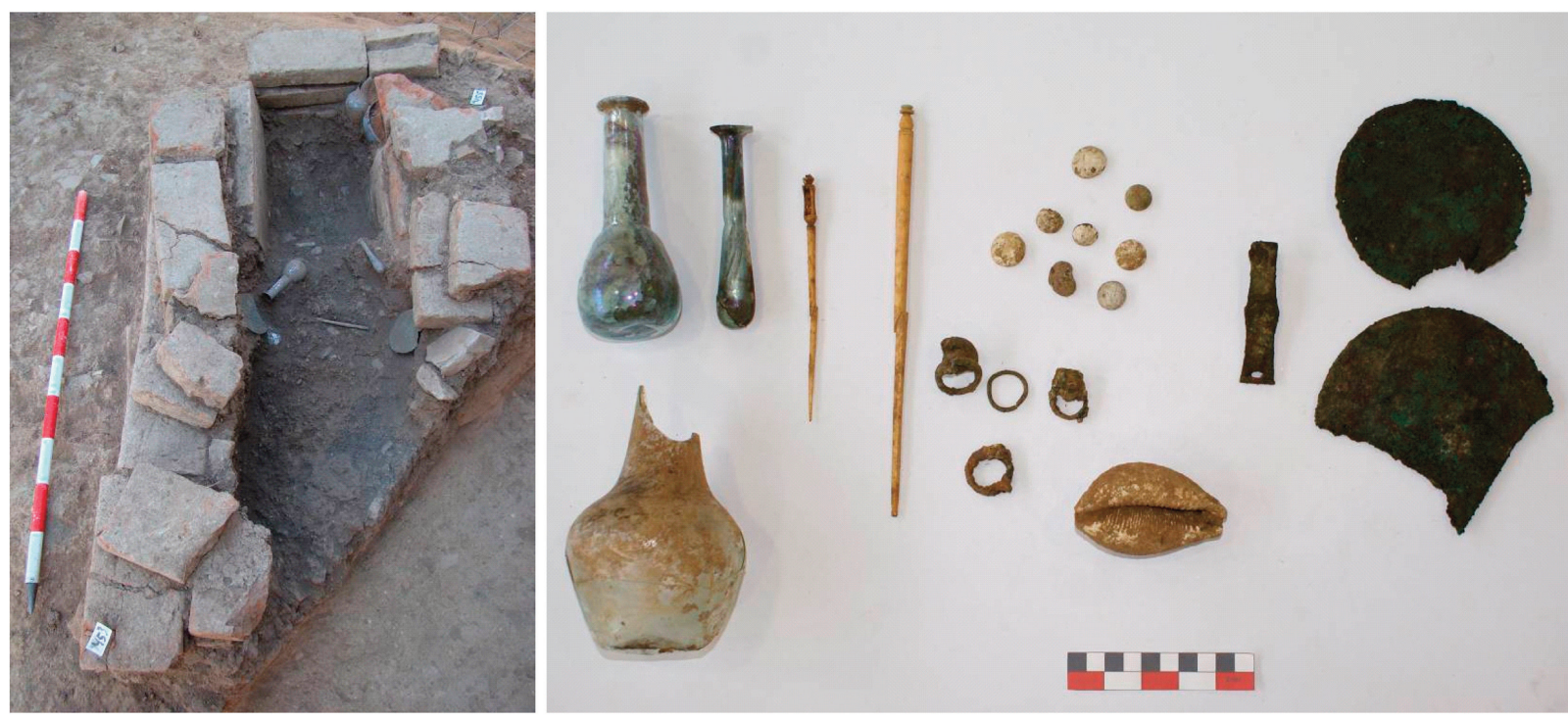

FIG. 3. Tumba en caja de ladrillo para incineración y depósito funerario de la sepultura excavada. 


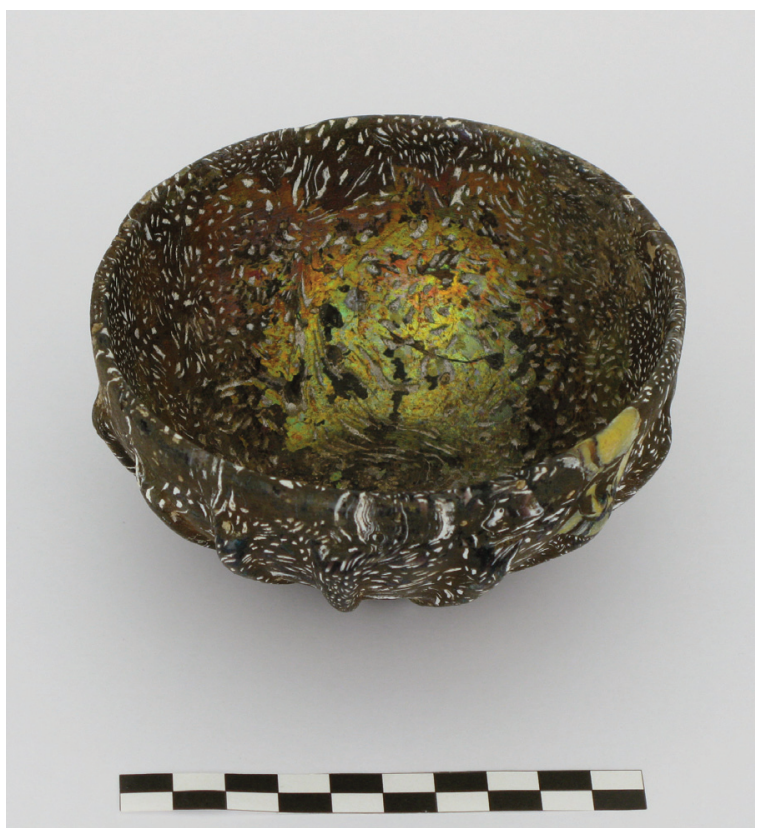

FIG. 4. Ejemplar de cuenco gallonado de pasta vitrea hallado en la tumba A39.

Los objetos mejor conservados son dos ungüentarios, uno del tipo Isings 8 y otro Isings 28, ambos fechables en la primera mitad del s. I d. C. Entre los objetos fragmentarios se encontró una pequeña botella de vidrio de color verdoso, de la que se conservaban el depósito y arranque de cuello además de una pequeña jarra y un cuenco. La jarrita es un ejemplar monoansado, de la forma Isings 56a, que tiene cuerpo ovoide, ancho cuello y pico vertedor que parece tratarse de una reminiscencia de las jarras de metal (Isings, 1956). En líneas generales, es un elemento doméstico usado para el servicio de mesa, como contenedor de agua y vino principalmente. En contexto funerario, su empleo forma parte del ritual pagano, junto con otros objetos de cerámica, metal o vidrio, que permiten al difunto participar en el banquete funerario. Por su parte, el cuenco se pudo identificar con un bol de vidrio verdoso con borde engrosado plegado sobre sí mismo, carena marcada y base con pie abierto.

El cuenco de costillas de pasta vítrea de la tumba A39 (Fig. 4) corresponde a la forma Isings $3 \mathrm{a}$ y ha sido creado empleando la técnica del vidrio fundido, conformado a molde y pulido a torno, con abrasivos en la cara interior y probablemente al fuego en la exterior (Isings, 1957; Arbáizar, 2003). Su decoración imita la piedra de jaspe y es de color ocre oscuro. Por sus características, esta pieza se data en los inicios de la primera centuria de nuestra era. Los lugares de producción de los ejemplares más tempranos están en la Península Itálica, aunque también se fabricaron en otros puntos del Mediterráneo occidental. En Mérida se han localizado numerosos ejemplares de cuencos decorados con costillas en la panza, aunque la mayoría corresponden a la variedad $3 c$, realizados en vidrio soplado-moldado y cuya procedencia está en Próximo Oriente (Caldera, 1983: 29).

Otros elementos encontrados en la tumba son ocho fichas o calculi de pasta vítrea, seis de ellas blancas y dos negras a las que se les atribuye un uso lúdico como parte de juegos de mesa o realizados en el suelo.

Los hallazgos de hueso se corresponden con tres acus crinalis de gran formato. Una primera pieza completa es una aguja del tipo Beal, A XVIII, que se usaba para extraer perfumes de los ungüentarios (Beal, 1983). Su cabeza, decorada con balaustre, remata en una punta plana precedida de banda decorativa incisa. Este ejemplar se fecha en la primera mitad del siglo I d. C.

El segundo elemento de hueso se halló fragmentado en dos partes y presenta una sección circular con remate en punta en un extremo y decorativo en la parte superior. La decoración corresponde a una pequeńa celda o jaula configurada por cuatro palos en cada esquina, en cuyo interior se encuentran tres bolitas de hueso. Su uso se considera ornamental. Una tercera aguja se identifica con un acus crinalis de punta redondeada (Vicente, 1995), que no conserva el extremo proximal y apareció calcinada. La aguja de pelo es uno de los elementos de uso personal femeninos más frecuentes en las excavaciones emeritenses (Rascón et al., 1995).

Entre las piezas metálicas destacan dos espejos de bronce de forma circular. Uno de ellos es un disco de unos $10 \mathrm{~cm}$ de diámetro al que le falta una pequeña porción de un extremo. Tiene una moldura decorativa exterior que delimita el perímetro de la pieza, con doble banda incisa, una 
interior y otra exterior, en cuya parte central se ha realizado una decoración con gráfila calada. El segundo es un ejemplar de unos $12 \mathrm{~cm}$ de diámetro al que le falta un tercio del disco y no presenta decoración. En general, los espejos de bronce reflejarían las imágenes gracias al pulimento de una de sus caras. Estos objetos son claramente instrumentos de tocador, asociados al género femenino en la sociedad romana.

Se han localizado también los diversos elementos metálicos de una caja o capsa, cuyas partes de madera habrían desaparecido. Entre sus componentes se documenta una bisagra de bronce compuesta de doble lámina unida por perno de hierro que permanece en su sitio. De las tres argollas de bronce encontradas, al menos dos se hallaban unidas mediante enganche a un remache que se uniría a la caja. Otro de los apliques de la caja sería una placa de bronce de sección rectangular provista de un orificio de enganche en un extremo y un resalte con orificio en el otro, donde se insertaría el elemento de cierre. Este tipo de objetos, que se encuentran frecuentemente en ámbito funerario, servían para guardar dinero, fichas, joyas, útiles de escritura, etc. Normalmente contarían con cerradura y, en algunos casos, con asas, adornos y remaches diferentes.

Un objeto de difícil identificación, por su morfología común a diversas tipologías, es un aro de bronce de sección circular de 2,2 cm de diámetro exterior y $0,2 \mathrm{~cm}$ de grosor. La lámina se repliega sobre sí misma, sin estar unida o soldada en el extremo de unión. Podría haber formado parte de la caja, como el resto de las argollas descritas, cuyos diámetros exteriores oscilan entre 1,9 y 2,4 cm, muy similares al del aro. Cabe también la posibilidad de que la pieza fuera un anillo de la persona enterrada en la sepultura.

Se halló también un stylus de hierro, muy mal conservado, que remata en una punta aguda en un extremo y en espátula en el otro. Se trata de un instrumento de escritura del que se han hallado numerosos ejemplares en las excavaciones de Mérida.

Finalmente, la presencia de una moneda de bronce facilita o corrobora la cronología ya propuesta gracias a los objetos muebles de datación más precisa. En el anverso, se aprecia un busto orientado a la izquierda, así como parte de la leyenda donde se puede leer: ...CAESAR AVG.... En el reverso se representa a Minerva con lanza y escudo. Por sus características parece tratarse de un as, posiblemente de Claudio, siendo segura una cronología de la primera mitad del siglo I d. C., en época julioclaudia (Cayón, 1985).

\subsection{Interpretación de la tumba en su área funeraria}

El enterramiento A39 se integra en un área funeraria muy extensa que ocupó el sector NE extramuros de la ciudad de Augusta Emerita, al menos entre los ss. I y IV d. C. Las sepulturas se organizan en torno a las dos vías citadas, encontrándose algunas en el interior de los recintos y mausoleos funerarios y disponiéndose otras aparentemente de manera aislada. Para el mantenimiento de las áreas funerarias, se crearon estructuras de riego, tales como pozos y acequias.

La tipología de la tumba A 39 es una cremación en caja de ladrillo y cubierta posiblemente también de ladrillos, si atendemos a los que se han conservado en la parte superior de la estructura. Tanto en incineraciones como en inhumaciones, la sepultura fabricada con ladrillos es uno de los modelos más empleados en todo el período romano, en sus diversas variantes. Al igual que en las sepulturas en fosa, se realizaban diversos ritos antes y después de la deposición del cadáver, que incluían fuegos purificadores, libaciones, etc. La tumba se enmarca en una serie de características que se desarrollan a lo largo del s. I, como son la preferencia por la incineración, la profusión de objetos en el interior de la tumba, predominando los vidrios, que son en su mayor parte producciones locales (VV. AA., 2012: 88-89). Desde la fundación de la colonia y aún en esta primera parte del s. I no es infrecuente la inclusión de algunos objetos de importación, como es nuestro caso, con el cuenco de pasta vítrea y la concha.

En el sector donde se encuentra la sepultura, el cuadrante NE del área excavada, se localiza un conjunto de sepulturas romanas altoimperiales fechado entre los ss. I-II d. C., donde se han documentado 24 enterramientos, todos de incineración. Generalmente, presentan un estado de conservación bastante deficiente, debido al expolio desde antiguo así como a la implantación en la zona de algunas construcciones moderno-contemporáneas. 
Se documentan tres tumbas con caja de ladrillo, incluyendo A39, destacando una con doble cámara; sepulturas tipo mensa, con revestimiento de opus signinum, del que se conservan siempre escasos restos y sólo con policromía en un caso; tumbas de tipo bustum, donde los restos han sido incinerados dentro de la misma fosa después usada como tumba; $y$, finalmente, enterramientos en fosa simple, donde se aprecian huellas de rubefacción en las paredes. En muchos de los casos estudiados, queda claro el empleo de la pira funeraria in situ, quedando restos alterados de la cremación del cadáver junto con los lígneos destinados a tal fin.

\section{El ejemplar de Cypraea pantherina: descripción taxonómica y distribución geográfica}

La determinación específica ha sido realizada mediante la clasificación linneana clásica. Para la identificación taxonómica han sido utilizados diferentes atlas malacológicos (Allan, 1956; Burgess, 1985; Lorenz y Hubert, 1993; inter alia) así como la colección de referencia del Departamento de Paleontología de la Facultad de Geología -Univ. de Barcelona-. La superficie del ejemplar han sido observada mediante lupa binocular -Optech $\mathrm{HZ} \times$ 10 a 45 aumentos- con el objeto de describir las posibles alteraciones del elemento original.

El ejemplar recuperado en la tumba A39 (Fig. 5) presenta forma ovalada, globosa en la cara dorsal y con apertura estrecha y dentada típica en los cauris -Cypraeidae - en la cara ventral. La concha es gruesa, de color blanco en la zona columelar y de color pardo claro con intenso moteado difuso en

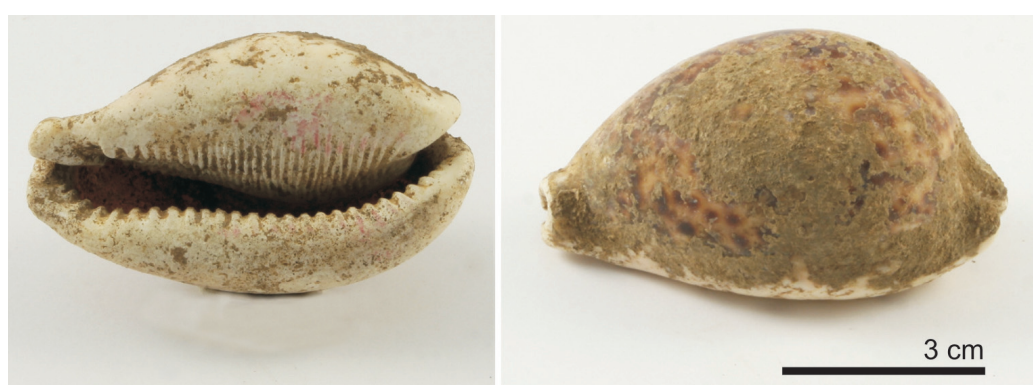

FIG. 5. Ejemplar de Cyprea pantherina recuperado como parte del depósito funerario. marrón en la cara dorsal. En esta última, presenta una línea difusa de color rojo que atraviesa el espécimen longitudinalmente. Las medidas tomadas en milímetros son de 79,2 x 52,6. Los caracteres taxonómicos expuestos indican que se trata de un ejemplar de concha de gasterópodo marino de la especie $C$. pantherina. El género al que pertenece este molusco marino - Cypraeidae- presenta dos especies muy similares morfológicamente, $C$. pantherina y $C$. tigris, si bien la primera presenta una concha más grácil y ligera, y la segunda cuenta por lo general con el labio externo y el columelar más separados y adornados por dientes de mayor tamańo (Allan, 1956). En cualquier caso, debemos tener en cuenta que ambas especies se encuentran estrechamente emparentadas a nivel filogenético (Meyer, 2003). Esta especie también es conocida por los siguientes sinónimos: Cypraea vinosa, Cypraea obtusa, Cypraea catulus y Phanteriana pantherina (Allan, 1956).

La $C$. pantherina es una especie indopacífica. $\mathrm{Su}$ rango biogeográfico se circunscribe al Mar Rojo, desde el golfo de Aqaba y el golfo de Suez al $\mathrm{N}$ hasta el golfo de Adén al $\mathrm{S}$, considerándose una especie endémica. Actualmente, puede encontrarse en el Mediterráneo oriental debido a la construcción del canal de Suez, siendo su distribución natural e histórica las costas poco profundas del Mar Rojo desde Egipto a Yemen. Por su parte la $C$. tigris puede encontrarse en toda la región indopacífica, sin ocupar el espacio de $C$. pantherina.

En el ejemplar presentado en este trabajo, el brillo típico de las conchas de esta especie se ha perdido seguramente por procesos postdeposicionales. Se observan restos de concreción de carbonatos en toda la superficie de la concha así como restos de coloración rojo-burdeos de origen desconocido en la zona columelar (Fig. 3).

\section{Conclusiones}

Las conchas de moluscos de procedencia indopacífica más comunes en el registro arqueomalacológico de Europa y el Mediterráneo 
pertenecen al género Cyprea-cauríes-, siendo muy comunes Cyprea annulus y Cyprea moneta, utilizadas como cuentas de collar, colgantes, adornos y materia prima para fabricar abalorios durante siglos (Allan, 1956; Reese, 1991).

Por su parte, la $C$. tigris y la $C$. pantherina, de mayor tamańo que las anteriores, se presentan de forma frecuente como parte de depósitos funerarios en la región euromediterránea desde la Edad del Bronce hasta la Alta Edad Media. Conchas completas de C. pantherinaltigris han sido halladas en tumbas de Rusia, Hungría, Italia, Austria, Alemania, Bélgica, Dinamarca, Suiza, Francia e Inglaterra (Fig. 4).

De la revisión realizada por Reese (1991) sobre la presencia de conchas indopacíficas en el Mediterráneo y Europa se obtienen dos grandes contextos arqueológicos para la especie documentada. Por un lado, este autor reconoce una serie de conchas de ambas especies que suelen presentarse modificadas mediante perforaciones simples o complejas en las que se insertan anillos, cadenas o pasadores de hierro y bronce. Este tipo de abalorios complejos se asocian a inhumaciones femeninas en todo el norte y centro de Europa, con una cronología que se sitúa en torno al siglo vili d. C. En ocasiones, las conchas forman parte de cinturones o fajas, o han sido utilizadas para confeccionar cuentas de collar. Se trata, por tanto, de elementos de adorno personal en los que las conchas de C. pantherinaltigris formaron parte del ajuar funerario de mujeres de origen germánico -anglos, sajones, vikingos, normandos, francos o merovingios- (Reese, 1991; Joseph, 2005).

Por otra parte y en relación directa con el ejemplar presentado en este trabajo, se encuentran una serie de conchas asociadas a contextos funerarios que se insertan plenamente en el mundo romano. En la mayoría de los casos documentados, las conchas suelen encontrarse aisladas (un único espécimen) y no presentan modificaciones antrópicas de su morfología natural, lo que apunta hacia un valor simbólico/estético per se de las conchas de dichas especies.

Encontramos distintos ejemplos asociados tanto a incineraciones, como la de Otranto en Italia del s. I a. C., como a inhumaciones del s. I d. C. en Nîmes y la necrópolis galorromana de Trion, en Francia (Reese, 1991; Maney, 1981). En todos los casos, las conchas aparecen asociadas a enterramientos femeninos presentándose como una constante a través del tiempo.

Fuera de contextos funerarios, un ejemplar de C. tigris fue recuperado en las excavaciones del Mitreo de Estrasburgo y conchas de $C$. pantherina y $C$. tigris se hallaron en las excavaciones históricas de Pompeya y Herculano - hasta un total de 48 ejemplares, de los que por desgracia desconocemos información de tipo contextual (Reese, 2002)- (Fig. 6).

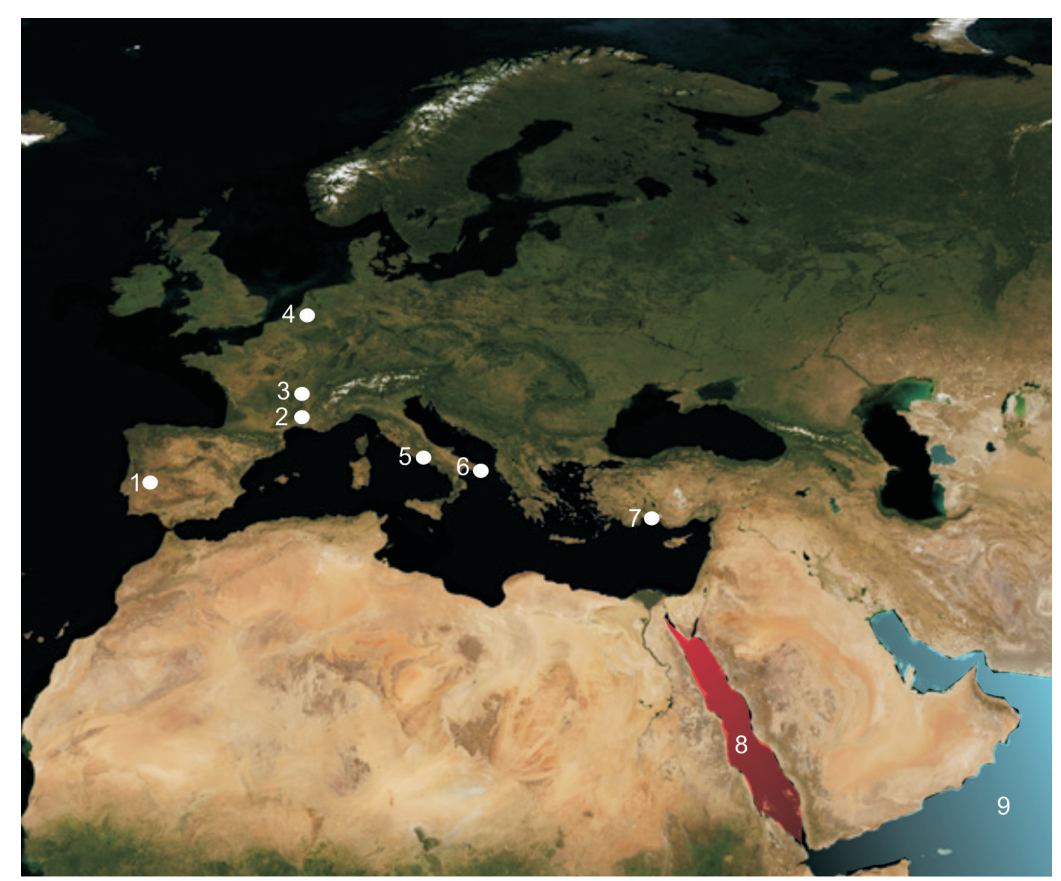

FIG. 6. Hallazgos de C. panterina/tigris en contextos greco-romanos y distribución natural de las dos especies: 1. Mérida; 2. Nîmes; 3. Trion; 4. Mitreo de Estrasburgo; 5. Pompeya y Herculano; 6. Otranto; 7. Templo de Venus de Cnido en Caria; 8. Distribución natural de C. pantherina $y$ 9. distribución natural de $\mathrm{C}$. tigris. 
Las conchas en general, y los cauris en particular, han estado asociados a la fertilidad y la feminidad tradicionalmente. El parecido de la cara columelar de estas conchas con los genitales femeninos, pero también con ojos entornados, las ha convertido para diferentes culturas en amuletos relacionados con la fertilidad y el mal de ojo. Plinio afirma que las conchas consagradas al templo de Venus en Cnide -Afrodita Cnidea- tienen propiedades especiales llevadas como amuletos ya que protegen en los partos difíciles y conducen a buen fin los partos en peligro. También nos informa de que las conchas conservadas en sal y llevadas como amuletos por una mujer embarazada provocan que la placenta y las membranas fetales sean expulsadas después de la salida del feto (Plin. NatHist., XXXII, 6, en Canto et. al., 2002). El caso emeritense puede inscribirse en este contexto cultural. El depósito funerario en el que se incluye nuestro ejemplar de $C$. pantherina ha sido fechado en el siglo I d. C. ( $c f$. apartado 2. 2) lo que coincide con los escasos paralelos documentados para conchas del mismo tipo asociadas a tumbas de época romana. La tumba debió pertenecer a un personaje femenino según se deriva de su contenido material, sobre todo por los espejos, agujas de pelo, el removedor y los contenedores de perfumes, además de por los dos objetos suntuosos como son el cuenco gallonado, que imita piedra semipreciosa y la propia concha de $C$. pantherina.

Teniendo en cuenta que lo más plausible es que el ejemplar presentado forme parte de un depósito funerario femenino, cabría preguntarse el sentido de tal ofrenda. Tal y como indicamos, la concha no presenta modificaciones de su estructura natural. Ninguno de los elementos metálicos o cuentas de pasta vítrea que forman parte del depósito excavado pertenece a un elemento de adorno complejo -tipo colgante o collar- que incluyese la concha de cauri. Por tanto, el elemento en sí mismo sin modificación alguna debió concentrar el carácter quizá mágico-religioso por el que fue elegido como elemento funerario. Los paralelos expuestos anteriormente nos llevan a decantarnos por esta interpretación. Sobre el origen de dicho elemento, poco podemos aportar con los datos recabados. Quizá la concha llegó a la ciudad de Augusta Emerita a través de las amplias redes comerciales plenamente desarrolladas en el Mediterráneo para este periodo o quizá fue transportada como parte de las pertenencias de una familia de origen oriental. Quizá el posible origen oriental del cuenco gallonado de pasta vítrea que acompañaba a la concha pueda estar relacionado. En cualquier caso, dejando aparte este tipo de especulaciones, el caso reportado en este trabajo arroja nueva luz sobre la extensión de una costumbre documentada en otras zonas del imperio entre los siglos I a. C. y I d. C.

\section{Bibliografía}

Allan, J. (1956): Cowry shells of the World seas. Melbourne: Georgian House.

Arbáizar, S. (2003): Vidrio en la Fundación Lázaro Galdiano. Madrid: FLG.

BEAL, J. (1983): Catalogue des objects de tabletterie de Museé de la Civilisation galloromain de Lyon. Nouvelle série. Lyon: Centre d'Études Romaines et Gallo-romaines de l'Université Jean Moulin III.

Burgess, C. M. (1985): Cowries of the world. Cape Town: Verhoef Seacomber Publications.

CALDERA, P. (1983): "El vidrio romano emeritense", Augusta Emerita, I, pp. 7-80.

CANTO, J.; GÓMEZ, I.; GonzÁlez, S. y TARriño, E. (2002): Plinio. Historia Natural (Libros de animales: VIII-XI, XXVIII-XXXII). Madrid: edit. Cátedra.

CAYÓN, J. R. (1985): Compendio de las monedas del Imperio Romano. Madrid, vols. III y IV.

IsINGS, C. (1957): Roman glass from dated finds. Djakarta: Universitas Gronongen.

Joseph, J. (2005): “A Twelfth Century Cowry", Pallidula, 35 (2), pp. 6-10.

Lorenz, F. L. y Hubert, A. (1993): A Guide to Worldwide Cowries. Wiesbaden: Chr. Hemmen Verlag.

Maney, A. L. (1981): Anglo-Saxon amulets and curing stones. BAR Intern. Ser., 96. Oxford: Archaeopress.

Meyer, C. P. (2003): "Molecular systematics of cowries (Gastropoda: Cypraeidae) and diversification patterns in the tropics", Biological Journal of the Linnean Society, 79, pp. 401-459. http://dx.doi.org/10.1046/j.1095-8312.2003.00197.x

PiCADO, Y. (2006): "Restos funerarios en torno a una vía de acceso a Emerita Augusta en la zona norte de Mérida", Mérida. Excavaciones arqueológicas 2003, 9, pp. 91-108.

Rascón, S.; POlO, G.; Pedreira y ROMÁN, P. (1995): "Contribución al conocimiento de algunas produc- 
ciones en hueso de la ciudad hispanorromana de Complutum: el caso de las acus crinalis", Espacio, Tiempo y Forma, Serie I, Prehistoria y Arqueología, 8, pp. 295-340.

ReEse, D. S. (1991): "The trade of Indo-pacific shells into the Mediterranean basin and Europe", Oxford Journal of Archaeology, 10 (2), pp. 159-167. http://dx.doi.org/10.1111/j.1468-0092.1991.tb00012.x

- (2002): "Marine invertebrates, freshwater shells and land snails. Evidence of specimens, mosaics, wall painting, sculpture, jewerly and roman authors". En Feemster, W. y Meyer, F. (eds.): The Natural History of Pompeii. Cambridge: CUP, pp. 292-314. VANHAEREN, M. y D'ERrico, F. (2006): “Aurignacian Ethno-Linguistic Geography of Europe Revealed by Personal Ornaments", Journal of Archaeological Science, 33 (8), pp. 1105-1128.

http://dx.doi.org/10.1016/j.jas.2005.11.017

VV. AA. (2012): El Consorcio y la arqueología emeritense. De la excavación al museo. Mérida. 